\section{Angiotensin II}

\author{
Danial E. Baker' and Terri L. Levien'
}

Hospital Pharmacy

2018, Vol. 53(4) 230-233

(C) The Author(s) 2018

Reprints and permissions:

sagepub.com/journalsPermissions.nav

DOI: 10.1 I77/00185787/8778224

journals.sagepub.com/home/hpx

@SAGE

\begin{abstract}
Each month, subscribers to The Formulary Monograph Service receive 5 to 6 well-documented monographs on drugs that are newly released or are in late phase 3 trials. The monographs are targeted to Pharmacy \& Therapeutics Committees. Subscribers also receive monthly I-page summary monographs on agents that are useful for agendas and pharmacy/nursing in-services. A comprehensive target drug utilization evaluation/medication use evaluation (DUE/MUE) is also provided each month. With a subscription, the monographs are available online to subscribers. Monographs can be customized to meet the needs of a facility. Through the cooperation of The Formulary, Hospital Pharmacy publishes selected reviews in this column. For more information about The Formulary Monograph Service, contact Wolters Kluwer customer service at 866-397-3433.
\end{abstract}

Generic Name: Angiotensin II

Proprietary Name: Giapreza (La Jolla Pharmaceutical Co) Approval Rating: $1 \mathrm{P}$

Therapeutic Class: Vasoactive Agents

Similar Drugs: Norepinephrine

Sound- or Look-Alike Names: Angiotensin II Receptor Blockers

\section{Indications}

Angiotensin II is approved to increase blood pressure in adults with septic or other distributive shock. ${ }^{1,2}$

\section{Clinical Pharmacology}

Angiotensin II is a vasoconstrictor that can increase blood pressure and aldosterone release. The vasoconstrictor effects of angiotensin II are the result of its direct action on the vessel wall, mediated by binding to the G-protein-coupled angiotensin II receptor type 1 on vascular smooth muscle cells, which stimulates $\mathrm{Ca}_{2}^{+} /$calmodulin-dependent phosphorylation of myosin and causes smooth muscle contraction. ${ }^{1}$

\section{Pharmacokinetics}

The plasma half-life of angiotensin II is less than 1 minute. Angiotensin II is metabolized by aminopeptidase A and angiotensin-converting enzyme 2 to angiotensin-(2-8) (angiotensin III) and angiotensin-(1-7), respectively, in plasma, erythrocytes, and other organs. Angiotensin II type 1 receptor-mediated activity of angiotensin III is approximately $40 \%$ of angiotensin II; however, aldosterone synthesis activity is similar to angiotensin II. Angiotensin-(1-7) exerts the opposite effects of angiotensin II on angiotensin II type 1 receptors and causes vasodilation. ${ }^{1}$
Clearance of angiotensin II is not dependent on renal or hepatic function. ${ }^{1}$

\section{Comparative Efficacy}

\section{Indication: Distributive Shock}

Vasopressors (eg, norepinephrine, vasopressin, vasopressin analogues) are used to stabilize critically ill patients during shock. The addition of angiotensin II to the drug regimen may reduce catecholamine vasopressor requirements. However, the exact role of angiotensin II in the treatment of distributive shock requires further investigation. ${ }^{3,4}$

\section{Studies}

Drug: Angiotensin II vs Placebo

Reference: Khanna A, et al, 2017 Angiotensin II for the Treatment of High-Output Shock 3 (ATHOS-3 trial) ${ }^{1,5}$

Study Design: Randomized, double-blind, placebocontrolled, multicenter study

Study Funding: La Jolla Pharmaceutical Company

Patients: 321 patients (18 years and older) with vasodilatory shock (cardiac index greater than $2.3 \mathrm{~L} / \mathrm{min} / \mathrm{m} 2$ or central venous oxygen saturation greater than $70 \%$ coupled with central venous pressure of more than $8 \mathrm{~mm} \mathrm{Hg}$, with a mean arterial pressure between 55 and $70 \mathrm{~mm} \mathrm{Hg}$ ) despite intravenous (IV) volume resuscitation with at least $25 \mathrm{~mL} / \mathrm{kg}$ of body weight over the previous 24 hours

'Washington State University, Spokane, USA

Corresponding Author:

Terri L. Levien, Clinical Professor, Pharmacotherapy Department, College of Pharmacy and Pharmaceutical Sciences, Washington State University, PO Box 1495, Spokane, WA 992 10-I495, USA.

Email: levient@wsu.edu 
and administration of high-dose vasopressors for at least 6 hours but no longer than 48 hours. Exclusion criteria included burns covering more than $20 \%$ of total body surface area (BSA), acute coronary syndrome, bronchospasm, liver failure, mesenteric ischemia, active bleeding, abdominal aortic aneurysm, or absolute neutrophil count less than $1000 / \mathrm{mm} 3$ or receiving venoarterial extracorporeal membrane oxygenation or treatment with high-dose glucocorticoids. Study baseline characteristics included in the prescribing information and the New Drug Application for angiotensin II were as follows: $61 \%$ were male; $80 \%$ were white, $10 \%$ black, and $4 \%$ Asian; and $48 \%$ were 65 years and older.

Intervention: Patients were randomly assigned (1:1) to receive angiotensin II or saline placebo. The starting infusion rate was equivalent to angiotensin II $20 \mathrm{ng} / \mathrm{kg} / \mathrm{min}$ and was adjusted during the first 3 hours to increase mean arterial pressure to at least $75 \mathrm{~mm} \mathrm{Hg}$. The maximum rate of administration of study drug or placebo was $200 \mathrm{ng} / \mathrm{kg} /$ min. Dose of standard-of-care vasopressors were held constant during the 3-hour adjustment phase, unless there was a safety concern. However, if the dose of the vasopressor had to be adjusted during the first 3 hours, the patient was classified as a nonresponder to study drug. After 3 hours 15 minutes, the study drug and other vasopressors could be adjusted to maintain a target mean arterial pressure between 65 and $75 \mathrm{~mm} \mathrm{Hg}$. The infusion rate of angiotensin II could be adjusted between 3 hours 15 minutes and 48 hours to a rate equivalent to a dose of 1.25 to $40 \mathrm{ng} / \mathrm{kg} / \mathrm{min}$. After 48 hours, the study infusion was discontinued per the protocol-specified tapering process. If background vasopressor dose was subsequently increased to more than $0.1 \mu \mathrm{g} / \mathrm{kg} /$ min of norepinephrine or equivalent, or if the patient became unstable, study medication could be resumed for up to 7 days; however, the study drug could not be restarted if it had been discontinued for more than 3 hours.

\section{Results}

\section{Primary End Point(s)}

- Proportion of patients achieving response at hour 3, with response defined as mean arterial pressure at least $75 \mathrm{~mm} \mathrm{Hg}$ or an increase in mean arterial pressure from baseline of at least $10 \mathrm{~mm} \mathrm{Hg}$, without an increase in the background vasopressor dose: $69.9 \%$ with angiotensin II and $23.4 \%$ with placebo $(P<.001$; odds ratio, $7.95 ; 95 \%$ confidence interval [CI], 4.76-13.3).

\section{Secondary End Point(s)}

- Mean arterial pressure increased by $12.5 \mathrm{~mm} \mathrm{Hg}$ with angiotensin II and $2.9 \mathrm{~mm} \mathrm{Hg}$ with placebo $(P<.001)$.
- Cardiovascular Sequential Organ Failure Assessment (SOFA) score at 48 hours was greater in the angioten$\sin$ II group than in the placebo group $(-1.75 \mathrm{vs}-1.28$; $P=.01)$. However, there were no differences in the other SOFA score components or in total SOFA score.

\section{Other End Point(s)}

- Mean change in norepinephrine-equivalent dose from baseline to hour 3 was -0.03 with angiotensin II and +0.03 with placebo $(P<.001)$.

- All-cause mortality at day 7 was $29 \%$ in the angiotensin II group and $35 \%$ in the placebo group (hazard ratio, $0.78 ; 95 \% \mathrm{CI}, 0.53-1.16 ; P=.22$ ).

- All-cause mortality at day 28 was $46 \%$ in the angiotensin II group and 54\% in the placebo group (hazard ratio, $0.78 ; 95 \% \mathrm{CI}, 0.57-1.07 ; P=.12$ ).

Comments: Randomization was in blocks, with stratification based on mean arterial pressure at screening (less than $65 \mathrm{~mm} \mathrm{Hg}$ or $65 \mathrm{~mm} \mathrm{Hg}$ or greater) and Acute Physiology and Chronic Health Evaluation II (APACHE II) score (30 or less, 31 to 40 , or 41 or higher [on a scale of 0 to 71 , with higher scores indicating greater disease severity]). The primary efficacy analysis used the modified intention-to-treat population (all patients who began receiving angiotensin II or placebo). Statistical analysis for the secondary efficacy end points was conducted using a hierarchical order. Missing data were imputed using the last-observation-carried-forward method for clinical efficacy; in patients with missing values owing to death, treatment was considered to have failed.

The study was conducted in 9 countries in North America, Australasia, and Europe. The combined patient data show angiotensin II efficacy was similar in men and women; white and nonwhite patients; and patients older and younger than age 65 years. ${ }^{6}$

Limitations: The study had a relatively small sample size and limited duration of exposure to the angiotensin II infusion.

\section{Contraindications, Warnings, and Precautions}

\section{Contraindications}

The product labeling states there are no known contraindications to use of angiotensin II. ${ }^{1}$ Though not stated in the product labeling, hypersensitivity reactions to angiotensin II or any of its inactive ingredients (eg, mannitol) should be considered.

\section{Warnings and Precautions}

A higher incidence of arterial and venous thrombotic and thromboembolic events was observed in patients who received 
angiotensin II compared with placebo-treated patients in the ATHOS-3 study (13\% vs 5\%). The major difference was regarding the frequency of deep venous thromboses. Concurrent venous thromboembolism prophylaxis should be prescribed in patients requiring angiotensin II therapy. ${ }^{1}$

There are no controlled studies of angiotensin II in pregnant women because septic or other distributive shock is a medical emergency. Delaying treatment in pregnant women with hypotension associated with septic or other distributive shock may increase the risk of maternal and fetal morbidity and mortality. ${ }^{1}$

No studies have been conducted to assess the presence of angiotensin II in human milk or its effects on breastfeeding infants or milk production. ${ }^{1}$

Safety and efficacy of angiotensin II have not been established in pediatric patients. ${ }^{1}$

\section{Adverse Reactions}

The most common adverse reactions (incidence of at least $4 \%$ and at least $1.5 \%$ higher rate than with placebo) associated with angiotensin II in the ATHOS-3 trial were thromboembolic events, thrombocytopenia, tachycardia, fungal infection, delirium, acidosis, hyperglycemia, and peripheral ischemia (see Table 1). ${ }^{1}$ All patients were receiving other vasopressors in addition to the study drug. ${ }^{1,5}$

A systematic review of 1124 studies determined the most common nonpressor effects associated with the use of IV angiotensin II included changes in plasma aldosterone, renal function, cardiac variables, and electrolytes. Adverse events

Table I. Angiotensin II Adverse Reactions ( $\geq 4 \%$ Incidence and $\geq 1.5 \%$ Higher Rate Than With Placebo) in the ATHOS-3 Trial. ${ }^{\prime}$

\begin{tabular}{lcc}
\hline Adverse event & $\begin{array}{c}\text { Angiotensin II } \\
(\mathrm{n}=163)\end{array}$ & $\begin{array}{c}\text { Placebo } \\
(\mathrm{n}=158)\end{array}$ \\
\hline Thromboembolic events & $12.9 \%$ & $5.1 \%$ \\
Deep vein thrombosis & $4.3 \%$ & $0 \%$ \\
Thrombocytopenia & $9.8 \%$ & $7 \%$ \\
Tachycardia & $8.6 \%$ & $5.7 \%$ \\
Fungal infection & $6.1 \%$ & $1.3 \%$ \\
Delirium & $5.5 \%$ & $0.6 \%$ \\
Acidosis & $5.5 \%$ & $0.6 \%$ \\
Hyperglycemia & $4.3 \%$ & $2.5 \%$ \\
Peripheral ischemia & $4.3 \%$ & $2.5 \%$ \\
\hline
\end{tabular}

were infrequent and included headache, chest pressure, and orthostatic symptoms. While very few serious adverse events occurred, exacerbation of asthma and congestive heart failure and one case of fatal cerebral hemorrhage were reported. A meta-analysis of these studies was not possible because of heterogeneity among the studies. ${ }^{7}$

\section{Drug Interactions}

Concomitant use with angiotensin-converting enzyme inhibitors may increase the patient's response to angiotensin II, while concomitant use with angiotensin II receptor blockers may decrease the patient's response to angiotensin II. ${ }^{1}$

\section{Recommended Monitoring}

Monitor blood pressure response. ${ }^{1}$

\section{Dosing}

The initial recommended dose of angiotensin II is $20 \mathrm{ng} / \mathrm{kg} /$ min by continuous IV infusion through a central venous line. The dose should be titrated every 5 minutes in increments of up to $15 \mathrm{ng} / \mathrm{kg} / \mathrm{min}$ as needed to achieve or maintain target blood pressure. The maximum dose should not exceed $80 \mathrm{ng} /$ $\mathrm{kg} / \mathrm{min}$ during the first 3 hours of treatment. The maintenance dose should not exceed $40 \mathrm{ng} / \mathrm{kg} / \mathrm{min}$. When the underlying shock is sufficiently improved, the dose of angiotensin II can be decreased every 5 to 15 minutes in increments of up to $15 \mathrm{ng} / \mathrm{kg} / \mathrm{min}$ based on the patient's blood pressure. $^{1}$

Prior to administration, the injection for IV infusion must be diluted with sodium chloride $0.9 \%$. ${ }^{1}$ The recommended dilutions are summarized in Table 2 . $^{1}$

\section{Product Availability}

Angiotensin II was approved in January $2018 .^{2}$ It is available as a clear, aqueous solution in $2.5 \mathrm{mg} / \mathrm{mL}$ and $5 \mathrm{mg}$ per $2 \mathrm{~mL}$ vials. ${ }^{1}$ The undiluted vials of angiotensin II should be stored refrigerated at $2^{\circ} \mathrm{C}$ to $8^{\circ} \mathrm{C}\left(36^{\circ} \mathrm{F}\right.$ to $\left.46^{\circ} \mathrm{F}\right) .{ }^{1}$

Diluted solution can be stored at room temperature or be refrigerated for up to 24 hours. After 24 hours, the diluted solution should be discarded. ${ }^{1}$

Table 2. Recommended Preparation of Diluted Angiotensin II Solution.'

\begin{tabular}{lcccr}
\hline Fluid restricted? & Vial strength & Withdrawal amount & Infusion bag size & Final concentration \\
\hline No & $2.5 \mathrm{mg} / \mathrm{mL}$ & $1 \mathrm{~mL}$ & $500 \mathrm{~mL}$ & $5000 \mathrm{ng} / \mathrm{mL}$ \\
Yes & $2.5 \mathrm{mg} / \mathrm{mL}$ & $1 \mathrm{~mL}$ & $250 \mathrm{~mL}$ & $10,000 \mathrm{ng} / \mathrm{mL}$ \\
& $5 \mathrm{mg} / 2 \mathrm{~mL}$ & $2 \mathrm{~mL}$ & $500 \mathrm{~mL}$ & $10,000 \mathrm{ng} / \mathrm{mL}$ \\
\hline
\end{tabular}




\section{Drug Safety/Risk Evaluation and Mitigation Strategy (REMS)}

No REMS is required for angiotensin II. $^{2}$

\section{Conclusion}

Angiotensin II is approved to increase blood pressure in adults with septic or other distributive shock. Some patients with vasodilatory shock treated with fluid and vasopressors may not achieve adequate changes in mean arterial blood pressure and may benefit from the addition of angiotensin II to the drug regimen. Patient factors that may dictate who will receive the greatest benefit from addition of angiotensin II have not been fully established. Postmarketing data will be essential in providing further implications for best use of this agent.

\section{Declaration of Conflicting Interests}

The author(s) declared no potential conflicts of interest with respect to the research, authorship, and/or publication of this article.

\section{Funding}

The author(s) received no financial support for the research, authorship, and/or publication of this article.

\section{References}

1. Giapreza (angiotensin II) [prescribing information]. San Diego, CA: La Jolla Pharmaceutical Company; December 2017.

2. Unger EF. NDA approval letter: Giapreza (angiotensin II) (NDA 209360). Food and Drug Administration. https://www. accessdata.fda.gov/drugsatfda_docs/appletter/2017/209360 Orig1s0001tr.pdf. Published December 21, 2017. Accessed January 23, 2018.

3. Antonucci E, Gleeson PJ, Annoni F, et al. Angiotensin II in refractory septic shock. Shock. 2017;47(5):560-566.

4. Jentzer JC, Vallabhajosyula S, Khanna AK, Chawla LS, Busse LW, Kashani KB. Management of refractory vasodilatory shock [published online ahead of print January 9, 2018]. Chest. 2018. doi:10.1016/j.chest.2017.12.021.

5. Khanna A, English SW, Wang XS, et al. Angiotensin II for the treatment of vasodilatory shock. $N$ Engl J Med. 2017; 377(5):419-430.

6. U.S. Food and Drug Administration. Drug Trials Snapshots: GIAPREZA. U.S. Food and Drug Administration. https://www. fda.gov/drugs/informationondrugs/ucm591648.htm. Published January 11, 2018. Accessed January 23, 2018.

7. Busse LW, Wang XS, Chalikonda DM, et al. Clinical experience with IV angiotensin II administration: a systematic review of safety. Crit Care Med. 2017;45(8):1285-1294. 